eISSN: 2659-6482

DOI: https://doi.org/10.14201/pmrt.23715

\title{
LA MÚSICA DE LIGETI EN SECUNDARIA A TRAVÉS DE 2001: UNA ODISEA DEL ESPACIO
}

\section{Ligeti's Music in Secondary Through 2001: A Space Odyssey}

\author{
Alejandro CANO PALOMO \\ (Conservatorio Profesional de Zamora) \\ alejandro.canpal@educa.jcyl.es
}

RESUMEN: El trabajo llevado a cabo en esta investigación se centra en el uso de los medios audiovisuales como recurso didáctico en el aula de música de la enseñanza secundaria española, así como la música del compositor húngaro G. Ligeti (1923-2006) y el uso de sus partituras en la película 2001: Una odisea del espacio (1968) del director Stanley Kubrick (1928-1999).

Tras la parte de investigación, se presenta una propuesta didáctica para el resto de la comunidad educativa, de posible aplicación a la hora de abordar la música de Ligeti y el concepto de música textural a través de la cinta de Kubrick y las piezas musicales Requiem, Lux Aeterna y Atmosphères, con materiales de elaboración propia.

Palabras clave: Ligeti; educación; audiovisual; Kubrick.

ABSTRACT: This is a research work focuses on the use of audiovisual media as a didactic resource in the music classroom of Spanish secondary education, the music of the Hungarian composer G. Ligeti (1923-2006) and the use of his scores in the film 2001: A Space Odyssey (1968) by director Stanley Kubrick (1928-1999).

After the research part, I work in a didactic proposal for the rest of the educational communit, with possible application when addressing Ligeti's music and the concept of textural music through the Kubrick film and the 
next musical pieces: Requiem, Lux Aeterna and Atmosphères, with educative materials on my own elaboration.

Keywords: Ligeti; education; audiovisual; Kubrick.

\section{INTRODUCCIÓN}

Sin ninguna duda, la música académica del siglo XX es uno de los períodos históricos que menos atención recibe en nuestra enseñanza musical, quedando normalmente relegada a un segundo plano ante otras épocas musicales y encontrando pocas herramientas pedagógicas que puedan servir de utilidad al docente interesado. Es por ello que, con la elaboración de la propuesta didáctica que en este artículo se desarrolla, se pretende aportar a la comunidad educativa de enseñanza secundaria una herramienta útil a la hora de abordar en la clase de Música las partituras de nuestra época y especialmente las del compositor húngaro G. Ligeti, a través del uso de los medios audiovisuales de los que disponemos en el aula, concretamente con extractos de la película 2001: Una odisea del espacio, así como incentivando la creatividad del alumnado, la interpretación e improvisación y el trabajo en equipo.

Ya que el objetivo de la asignatura de Música dentro de la enseñanza secundaria no es, ni puede pretender ser, el de dar a conocer en profundidad los conceptos de armonía, contrapunto, timbre, etc., y el tratamiento de cada uno de estos parámetros en cada período musical, pues el tiempo del que disponemos los profesores es limitado, los recursos audiovisuales pueden ser un apoyo fantástico a la hora de abordar la música de las últimas décadas y ayudar al alumno a comprender el concepto creativo del compositor, y es en este sentido hacia el que se orientan todas las actividades de la propuesta, en ayudar al alumnado a captar la idea general del proceso creativo de Ligeti a través de sencillas partituras proyectadas en vídeo y de la propia interpretación de estas.

Mientras que la propuesta didáctica podrá encontrarla el lector en la segunda parte del artículo, la primera de ellas está enfocada hacia un breve análisis histórico del uso de la música de Ligeti en el cine, así como de algunas otras piezas de compositores de vanguardia, con el propósito de contextualizar las imágenes que sustentan los recursos audiovisuales de la propuesta didáctica.

\section{LIGETI EN EL CINE}

Cabe decir que las inclusiones de obras para salas de concierto en el cine han sido muchas y aunque el gran cupo de estas sean obras comprendidas entre el barroco y 
el romanticismo tardío, no han sido pocos los directores de cine que han recurrido a obras ya escritas de compositores contemporáneos o que incluso han contratado los servicios de estos para realizar nueva música exprofeso para el film en un lenguaje de vanguardia. Solo algunos ejemplos que corroboren este hecho pueden ser Planeta probibido (dir. Fred M. Wilcox, 1956), con música original de Louis Barron y Bebe Barron; El planeta de los simios (dir. Franklin J. Schaffner, 1968), con partitura original de Jerry Goldsmith; El manuscrito encontrado en Zaragoza (dir. Wojciech Has, 1965), con música original de K. Penderecki; El resplandor (dir. Stanley Kubrick, 1980), con partituras adaptadas tanto de Ligeti como de Penderecki y B. Bartók; El exorcista (dir. William Friedkin, 1973), con música adaptada de Penderecki, y una cita actual para cerrar la lista de ejemplos, la serie televisiva de HBO The new pope (dir. Paolo Sorrentino, 2019), con música de G. Crumb y Arvö Part.

Como se deduce del párrafo anterior, son varias las cintas cinematográficas en las que se han utilizado piezas del compositor húngaro, siendo además un caso extraordinario ya que en ningún caso desarrolló una partitura para la película, todas sus participaciones han sido con música ya escrita anteriormente para las salas de concierto. Esta inmersión en el cine de Ligeti no se podría entender sin el director de cine Stanley Kubrick, quien utilizó la música del compositor en hasta tres ocasiones, con las ya mencionadas El resplandor, 2001: Una odisea del espacio y Eyes wide shut.

El caso más interesante aquí para el desarrollo de la posterior propuesta didáctica es el de 2001: Una odisea del espacio, cinta que utilizaremos en el aula por su relevancia dentro de la historia cinematográfica, por ser perfectamente adecuada a la edad de los alumnos y por facilitar el entendimiento de la música del compositor húngaro debido a la gran cantidad de puntos de sincronía.

Es curioso el modo en el que Kubrick llega a conocer la música de Ligeti. Mientras que Alex North estaba ya trabajando en la banda sonora de la película, la esposa de Kubrick oye en la BBC el Requiem de Ligeti en 1967 y se lo hace escuchar a su marido, quedando este impresionado por la música y decidiéndose a utilizarla en la cinta (Centeno, 2016). Aunque el compositor fue reacio al inicio ante la idea de ceder los derechos de sus partituras a la Metro Goldwyn Mayer Studios (MGM, fundada en 1924), finalmente accedió suponiendo esto un gran reconocimiento por parte del público general hacia su obra. Aparte del Requiem de Ligeti, concretamente el «Kyrie», también se utilizó Lux aeterna y Atmosphères para la película. A continuación, se presenta un breve análisis de estas piezas con la escena en la que se utilizan. 


\subsubsection{1: Una odisea del espacio. Requiem («Kyrie»). Primera aparición}

Las primeras notas de Ligeti en esta película se reproducen en la escena en la que los simios encuentran el monolito negro. Al principio se alborotan con la presencia de este ente extraño, pero, poco a poco, se acercan hasta tocarlo, terminando la secuencia con un plano del monolito alineado con la Luna y el Sol. En esta escena, Kubrick nos presenta el Requiem como una especie de leitmotiv que asociaremos a lo largo de la película con el monolito y la inteligencia superior extraterrestre, ya que aparecerá más veces a lo largo de la cinta como se verá posteriormente. José Luis Centeno (2016: 214-219) destaca cuatro puntos de sincronía principales entre la música y la escena. Es notorio resaltar que Kubrick grabó la secuencia a partir de la música, como si de un videoclip musical se tratase, para poder establecer estos puntos sincrónicos con la música ya existente (North, 1970). Los puntos resaltados por Centeno son:

\begin{tabular}{|c|l|}
\hline \multicolumn{2}{|c|}{ Tabla 1. Puntos de sincronía en la primera escena del «Kyrie» } \\
\hline Tiempo de película & \multicolumn{1}{c|}{ Punto sincrónico } \\
\hline $00: 12: 29$ & $\begin{array}{l}\text { Se produce un cambio a gran plano del monolito y los } \\
\text { simios comienzan a acercarse, coincidiendo con un cambio } \\
\text { de registro y de intensidad. }\end{array}$ \\
\hline $00: 13: 09$ & $\begin{array}{l}\text { El líder de los simios comienza a acercarse al monolito } \\
\text { con el comienzo de una nota grave muy marcada. }\end{array}$ \\
\hline $00: 13: 25$ & $\begin{array}{l}\text { Cambio de plano y el líder está muy cerca del monolito. } \\
\text { La nota grave que comenzase anteriormente llega a su } \\
\text { máximo punto de intensidad. }\end{array}$ \\
\hline $00: 13: 39$ & $\begin{array}{l}\text { El simio líder toca el monolito y comienzan a distinguirse } \\
\text { palabras en el coro, así como una crecida de intensidad } \\
\text { general y subida de registro hacia el agudo. }\end{array}$ \\
\hline
\end{tabular}

Nota: Tabla de elaboración propia a partir de los datos aportados por Jose Luis Centeno en su tesis doctoral.

La música finaliza con la alineación del monolito y los astros, donde el «Kyrie» alcanza su mayor punto de intensidad.

Es curioso que Kubrick eligiese una pieza de carácter religioso para esta secuencia, y probablemente haya connotaciones personales del director detrás, pero sin duda alguna la música funciona perfectamente en la escena, ya que tanto la crecida de intensidad y registro como la aparición de las primeras palabras del 
coro casi ininteligibles dan una fuerza expresiva a la imagen que difícilmente se habría logrado con otra música. Sobre el hecho de la letra y su uso en esta escena, precisamente Chion (2001) destaca que sería imposible concretar el significado que Kubrick quiso otorgarle, pero se podría especular con varias hipótesis. La primera de ellas según el francés es que, al tratarse de una letra casi imposible de entender, da la sensación de que podrían incluso no ser seres humanos los que producen esas voces, relacionando por tanto la llegada del monolito con la inteligencia superior. La segunda hipótesis es que se podría interpretar como un lamento colectivo de los simios que se resolverá con las consecuencias que trae la llegada del monolito. Para Raúl Alda (2000), el Requiem ayuda a reforzar la idea de la llegada de una inteligencia superior con el monolito, representada a través del habla ininteligible por parte del coro, en la línea de la primera hipótesis de Chion, mientras que, para Carolyn Geduld (1973), la pieza musical introduce la idea de lo desconocido y sirve como advertencia de que este monolito traerá consecuencias trascendentales.

En mi opinión personal, creo que Kubrick elige la obra primero por la tensión que genera lentamente y en crescendo desde el primer momento, ideal para la escena en la que la propia imagen sin música ya sugiere esta tensión. En segundo lugar, comparto la idea de Raúl Alda y Chion, la asociación del habla ininteligible con el monolito y la inteligencia superior. Y, por último y en tercer lugar, por motivos religiosos. El propio Kubrick se definía como no creyente de ninguna religión monoteísta, pero destacaba la intriga que le suscitaba la idea de una inteligencia superior (Dios) y reconoce que el concepto de Dios está muy presente en la película (Agel, 1970).

\subsection{1: Una odisea del espacio. Requiem ("Kyrie»). Segunda aparición}

La siguiente representación de esta pieza en la película vuelve a estar relacionada con el monolito, funcionando como una especie de leitmotiv. En esta ocasión son los científicos los que se acercan al monolito, de manera similar a como lo hiciesen los simios en la escena analizada anteriormente. Incluso el Dr. Floyd (personaje de la película), fascinado por el descubrimiento, se acerca lentamente hasta él para tocarlo de un modo semejante al líder de los simios, aunque en esta ocasión con mayor convicción y desde una perspectiva distinta, la de la ciencia y la curiosidad por descubrir de qué se trata.

En el análisis de esta escena por varios autores se distinguen tres líneas principales. Por una parte, José Luis Centeno (2016) destaca que podría considerarse incluso el Requiem como música diegética producida por el monolito, aunque en ninguna de las dos escenas los personajes hacen pensar que esto sea así, ya que no hay referencias a que presientan o escuchen ningún tipo de música alrededor del monolito. Una segunda línea se decanta por pensar que el «Kyrie» pudiese ser 
tratado como leitmotiv. Para Alda (2000), por ejemplo, la música de Ligeti sigue representando lo desconocido y la inteligencia superior, mientras que Joan Padrol (2008) se define dentro de una posición parecida, destacando el gran poder que ejerce la pieza como leitmotiv y su capacidad de asociación entre el desconcierto y el misterio provocado por el monolito. La última y tercera postura de análisis se dirige hacia la imposibilidad de concebir la música de Ligeti sin considerar el resto de la banda sonora. Michel Climent (2000) considera que mientras la partitura de Strauss o Kachaturian representan al hombre y su evolución desde el simio, la música de Ligeti, por sus propias características, es ideal para representar la idea de una tecnología avanzada propia de una inteligencia superior no terrestre. Lee Gengaro (2014) también sigue en esta línea, ya que, según el autor, la música de Ligeti solo aparece cuando se hacen referencias en la película a ideas extraterrestres, mientras que la música que conforma el resto de la banda sonora representa la humanidad.

Personalmente me decanto por la segunda línea, ya que es tal la fuerza que ejerce la música del Requiem sobre la imagen que es imposible no asociar esta escena con la de los simios cuando aparece el monolito y la pieza musical. No obstante, comparto con Michel Climent y Lee Gengaro el efecto tan distinto que crearía esta música si toda la banda sonora fuera igual, viendo yo también una fuerte relación entre la partitura de Ligeti y la vida extraterrestre, que al final no deja de ser también un leitmotiv. En el primer caso se asocia Monolito con Requiem, y en el segundo caso Música de Ligeti con vida extraterrestre.

Jose Luis Centeno (2016: 220-226) vuelve a destacar algunas sincronías blandas en esta segunda escena con el «Kyrie»:

\begin{tabular}{|c|l|}
\hline \multicolumn{2}{|c|}{ Tabla 2. Puntos de sincronía en la segunda escena del «Kyrie» } \\
\hline Tiempo de película & \multicolumn{1}{|c|}{ Punto sincrónico } \\
\hline $52: 08$ & $\begin{array}{l}\text { Coincide la subida en intensidad de las voces femeninas } \\
\text { con el comienzo de la bajada de los científicos por la } \\
\text { rampa. }\end{array}$ \\
\hline $52: 30$ & $\begin{array}{l}\text { Mientras están bajando por la rampa se escucha una nota } \\
\text { tenida en el viento. }\end{array}$ \\
\hline $52: 57$ & $\begin{array}{l}\text { Se comienzan a distinguir sílabas con la llegada al final de } \\
\text { la rampa. }\end{array}$ \\
\hline $53: 00$ & $\begin{array}{l}\text { Las voces agudas comienzan a subir hacia el agudo } \\
\text { precipitadamente cuando se acercan al monolito. }\end{array}$ \\
\hline
\end{tabular}




\begin{tabular}{|c|l|}
\hline \multicolumn{2}{|c|}{ Tabla 2. Puntos de sincronía en la segunda escena del «Kyrie» } \\
\hline Tiempo de película & \multicolumn{1}{|c|}{ Punto sincrónico } \\
\hline $53: 12$ & $\begin{array}{l}\text { Con las primeras fotos por parte de los científicos } \\
\text { comienzan de nuevo las voces femeninas. }\end{array}$ \\
\hline $53: 26$ & $\begin{array}{l}\text { Es quizás el punto de mayor tensión, ya que tocan el } \\
\text { monolito. Voces femeninas en registro muy agudo. }\end{array}$ \\
\hline $53: 59$ & $\begin{array}{l}\text { Cambio a voces masculinas cuando se hacen la foto con } \\
\text { el monolito. }\end{array}$ \\
\hline
\end{tabular}

Nota: Tabla de elaboración propia a partir de los datos aportados por Jose Luis Centeno en su tesis doctoral.

Como se ha comentado anteriormente en más de una ocasión, estas escenas fueron grabadas y diseñadas a partir de la música, por lo que podría intuirse que se hizo una separación entre las voces femeninas y las masculinas, ya que, por cada nuevo evento que realizan los científicos, las voces femeninas son las protagonistas, mientras que, por los eventos relacionados directamente con el monolito, las voces principales son las masculinas.

\subsection{1: Una odisea del espacio. Lux Aeterna}

Esta segunda pieza del compositor húngaro aparece entre las dos escenas analizadas hasta ahora. Tras encontrar en la Luna un monolito muy similar al que hallaron los simios al comienzo, conducen hacia la excavación al Dr. Floyd. La música, también coral, enlaza muy bien con la segunda aparición del Requiem cuando comiencen a bajar la rampa el grupo de científicos y hace presagiar al espectador que algo misterioso y desconocido está cerca, así como la soledad del desierto lunar.

Para Chion (2001), las voces femeninas que predominan en la escena tienen una connotación claramente religiosa. Yo, personalmente, sigo viendo una asociación tímbrica entre voz femenina-científicos y voz masculina-monolito, dentro del leitmotiv Ligeti-extraterrestre.

\subsubsection{1: Una odisea del espacio. Atmosphères $y$ Requiem («Kyrie»)}

Es la última pieza de Ligeti utilizada en la película. Aparece al final, en la escena en la que Bowman (personaje de la película) realiza el viaje hacia el planeta de los extraterrestres. Kubrick nuevamente vuelve a rodar la escena a partir de 
la música, por lo que hay una perfecta sincronía entre imagen y partitura. Por ejemplo, los cambios tímbricos de la orquesta coinciden con cambios texturales visuales y los cambios de intensidad coinciden con el ojo de Bowman. Así mismo, la combinación entre las imágenes abstractas que vemos en escena (el viaje hacia lo desconocido) con la música es perfecta, tanto a nivel técnico como conceptual. Tanto para Geduld (1973) como para Padrol (2008), si la música se hubiera compuesto a partir de la imagen, como suele ser habitual en las bandas sonoras, no hubiera quedado tan bien sincronizada, ya que en este caso fue Kubrick quien puso la imagen sobre la partitura con una idea muy clara de lo que quería representar en escena. Chion también toma esta posición, destacando el papel tan importante que realiza la música de Ligeti sobre la escena, convirtiendo la visión de la película en una gran experiencia sensorial. Para el experto analista, la escena es el mejor ejemplo de cómo Kubrick utiliza la música durante toda la película, recordándole al cine mudo y la importancia y peso de la imagen y su relación con la partitura.

Personalmente, en esta escena sigo viendo una intención muy clara de relacionar a Ligeti con el mundo extraterrestre y un refuerzo de la asociación antes comentada de voces femeninas con científicos o humanos cerca del monolito y voces masculinas con el monolito en sí. La escena comienza con el monolito y el Requiem, leitmotiv ya evidente en este punto, y música coral, como hasta ahora siempre que aparecían la música de Ligeti y el monolito en cualquiera que fuese la situación. A partir de aquí, desaparecen el monolito y el «Kyrie» para dar paso a Atmosphères, la única pieza orquestal de Ligeti, precisamente cuando ya el ser humano se dirige hacia la vida extraterrestre y deja atrás el monolito, el ser humano ha roto la línea que lo separaba de esta inteligencia superior.

Sin ninguna duda, la música da la sensación de ser perfecta para la imagen, porque, en realidad, la imagen es perfecta para la música, ya que, como comentan el resto de autores, todos los cambios visuales están establecidos en relación a la partitura del compositor.

José Luis Centeno (2016: 231-237) vuelve a destacar varias sincronías blandas:

\begin{tabular}{|c|c|}
\hline \multicolumn{2}{|c|}{ Tabla 3. Puntos de sincronía en la tercera escena del «Kyrie» junto con } \\
Atmosphères
\end{tabular}




\begin{tabular}{|c|l|}
\hline \multicolumn{2}{|c|}{ Tabla 3. Puntos de sincronía en la tercera escena del «Kyrie» junto con } \\
Atmosphères
\end{tabular}

Nota: Tabla de elaboración propia a partir de los datos aportados por José Luis Centeno en su tesis doctoral.

\section{PROPUESTA DIDÁCTICA}

La propuesta didáctica que aquí se presenta está pensada para trabajar algunos

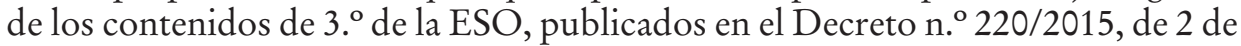
septiembre de 2015, de la Región de Murcia, especialmente de los tres primeros bloques: Interpretación y creación, Escucha y Contextos musicales y culturales. No obstante, con alguna adaptación por parte del docente, la propuesta didáctica puede ser perfectamente válida para otros niveles educativos.

El objetivo principal propuesto es la enseñanza de la música textural a través de las obras más representativas de Ligeti usadas en la película 2001: Una odisea del espacio, a través de una serie de actividades apoyadas en imágenes de la película mediante videogramas de elaboración propia.

\subsection{Actividad teórica}

Es recomendable que se le presente al alumnado la música de Ligeti dentro de un contexto adecuado, como es el de las músicas del siglo XX. Hay que tener presente que, salvo contadas excepciones, casi todo el contacto que haya tenido 
el alumno con la música hasta el momento habrá sido con estilos enmarcados dentro del sistema tonal, por lo que, si ya con anterioridad se han visto en clase otros sistemas armónicos como el dodecafonismo u otros modos de estructurar la obra musical como los propios del serialismo, la comprensión por parte del alumno de la búsqueda realizada por Ligeti y sus contemporáneos será más fluida y causará menos perplejidad, aunque, en cualquier caso, no es obligado que se hayan de ver previamente estos sistemas.

En este primer contacto por parte de los alumnos con el compositor G. Ligeti y su música, el profesor deberá exponer las ideas principales sobre las que se basan las partituras del compositor húngaro, prestando especial atención a la creación musical por texturas, pues será más accesible de este modo para los alumnos y además el resto de actividades van orientadas hacia la asimilación de este concepto y la relación por parte del alumno de Ligeti - Música textural.

Se recomienda al profesor realizar comparaciones entre esta música y los distintos filtros o capas de una fotografía, pues los adolescentes están plenamente familiarizados con esta idea gracias a las distintas aplicaciones de redes sociales que utilizan en su día a día y puede ayudarles a obtener rápidamente una idea general del proceso compositivo de la obra. En la plataforma virtual Youtube se pueden encontrar varios videogramas que muestran de una manera clara y sencilla la superposición de capas durante la obra, muy útiles para un primer contacto con esta música y como apoyo a la explicación teórica, como, por ejemplo: https:// www.youtube.com/watch?v=Zy8SQ-LWC20 (consultada el 21 de julio de 2020).

\subsection{1: Una odisea del espacio}

Una vez explicada la parte teórica, sería aconsejable hablarles brevemente a los alumnos de la película 2001: Una odisea del espacio, puesto que van a acercarse a Ligeti a través de esta cinta. Es importante que sepan qué tres piezas aparecen en la película («Kyrie», Lux Aeterna y Atmosphères) y el contexto en el que se utilizan, aunque no es necesario que hayan visto el film entero ni conozcan toda la trama que se desarrolla. Si anteriormente se han visto en clase otros ejemplos de música en el cine o se han explicado los conceptos de música diegética y extradiegética, puntos de sincronía o leitmotiv, puede ser adecuado recordar estos conceptos para una mayor profundización del aprendizaje, aunque no obstante todas las actividades están pensadas para realizarlas por completo sin que el alumnado haya visto anteriormente estos conceptos. 


\subsection{Actividades prácticas}

Captada la esencia de la música textural por parte del alumno y entendido el contexto en que se van a realizar las actividades, es momento de pasar a la parte práctica de la propuesta didáctica.

La primera pieza con la que se trabajará es el «Kyrie» del Requiem de Ligeti. Ya que esta misma partitura aparece en dos escenas de la película, se ha considerado la primera de ellas, cuando los simios encuentran el monolito, como la más adecuada, porque la imagen acompaña mejor a la música haciendo más evidente el aumento de tensión que se produce por la acumulación de texturas y, por tanto, más comprensible el proceso creativo seguido por el compositor.

Para realizar la actividad será necesario dividir a los alumnos en cuatro grupos, asociando a cada uno de ellos un instrumento o varios siempre que coincidan en registro. Por ejemplo, el grupo uno puede interpretar con cajas chinas o similares, el grupo dos con xilófonos o similares, el grupo tres con palmadas y voz y el cuarto grupo con cajón flamenco y zapateado en el suelo. La elección de los instrumentos dependerá de los medios con los que contemos en clase y, aunque lo ideal sería que tuviéramos una amplia riqueza tímbrica, el ejercicio puede realizarse sin ningún tipo de pérdida didáctica únicamente con el propio cuerpo como instrumento.

Cada grupo se asociará a uno de los siguientes colores: rojo, azul, verde y amarillo, siendo los colores rojo y azul los que entrañan una mayor dificultad rítmica y memorística para el alumno, mientras que los colores verde y amarillo son de dificultad media. De este modo, el profesor podrá dividir a los alumnos según sus características y así equilibrar la complejidad instrumental con la rítmica. Una vez establecidos los grupos y los instrumentos, se les entregará a los alumnos la partitura correspondiente a su grupo de color ${ }^{1}$. A continuación se detalla la partitura del grupo rojo, que sirve como ejemplo para todo el resto:

1. Todo el material necesario para realizar la propuesta didáctica se encuentra en https:// drive.google.com/drive/folders/1c_kzUKDBZKQn5iHnhU-yh674qqdZF3KW?usp=sharing. 


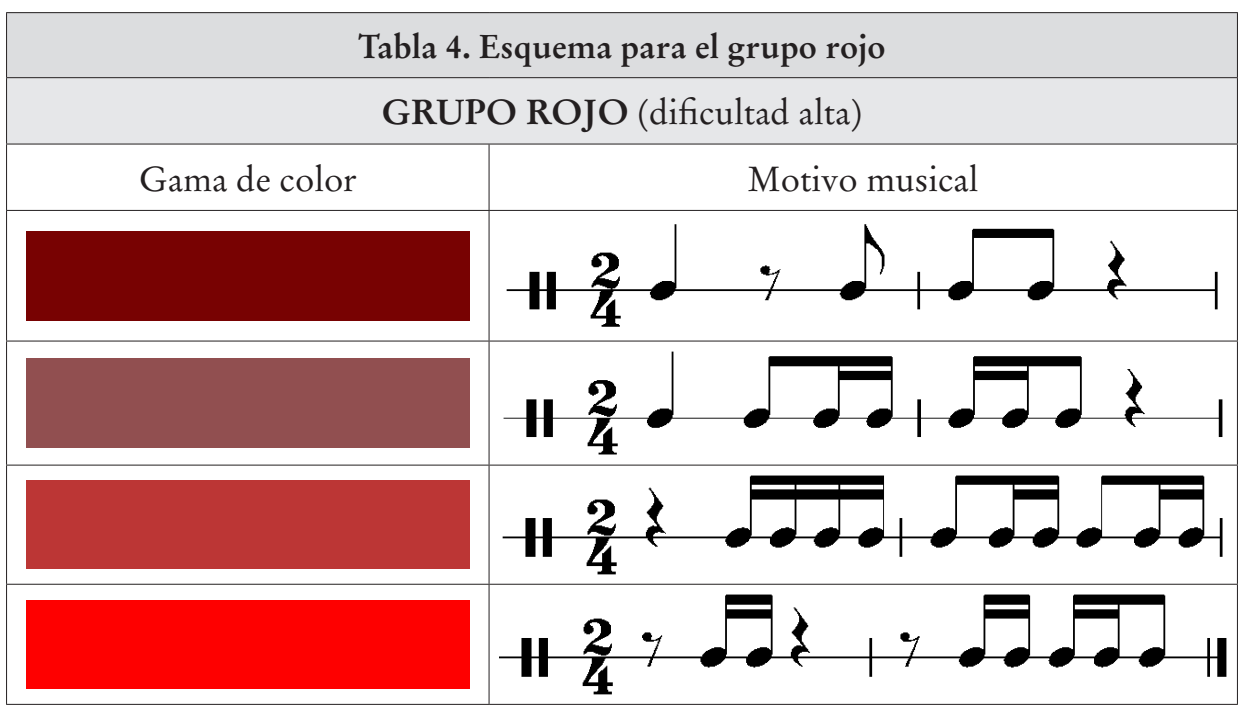

Nota: Elaboración propia.

Cada grupo, como se aprecia en la tabla anterior, dispone de varias gamas del color con un motivo musical asignado. En la partitura, el alumno también encontrará una tabla como la siguiente (Tabla 5), en la que se especifica cómo se interpretará en el instrumento cada una de las figuras musicales de los motivos anteriores. En los materiales aportados aparece en blanco la columna derecha de esta tabla, pues las indicaciones de interpretación instrumental están estrechamente ligadas con los instrumentos de que se disponga en clase, por lo que será el docente quien señale a los alumnos estas interpretaciones para que ellos las escriban en la tabla. El ejemplo a continuación se ha pensado para caja china y voz.

\begin{tabular}{|c|c|}
\hline \multicolumn{2}{|c|}{ Tabla 5. Ejemplo de rítmica para grupo rojo } \\
\hline Figura & Interpretación instrumental \\
\hline Negra & Golpe en la caja, dinámica forte \\
\hline Corchea & Sílaba con la letra «a» en registro agudo, dinámica piano. \\
\hline
\end{tabular}

Ediciones Universidad de Salamanca / 
ALEJANDRO CANO PALOMO

LA MÚSICA DE LIGETI EN SECUNDARIA A TRAVÉS DE 2001: UNA ODISEA DEL ESPACIO

\begin{tabular}{|c|c|}
\hline \multicolumn{2}{|c|}{ Tabla 5. Ejemplo de rítmica para grupo rojo } \\
\hline Figura & Interpretación instrumental \\
\hline \\
\hline
\end{tabular}

Nota: Elaboración propia.

Una vez que todos los alumnos estén divididos por grupos, con los instrumentos asignados y su partitura completa, se proyectará el vídeo Kyrie con partitura $(\text { enlace })^{2}$.

La interpretación con vídeo funciona del siguiente modo: sobre la escena de la película en la que aparece la pieza a trabajar se ha insertado una franja vertical blanca. Hacia ella se irán acercando bloques de colores, correspondientes a las gamas de la partitura de cada grupo. En el momento en el que el bloque de color toca la línea blanca, los alumnos deben comenzar a interpretar el motivo musical correspondiente, finalizando este cuando el bloque haya traspasado por completo la franja vertical.

De este modo, con la partitura y el vídeo, el alumno sabe cuándo debe comenzar su interpretación y cuándo finalizar o cambiar hacia otro motivo distinto. Para que el profesor pueda ejercer de director, se ha creado el vídeo Kyrie sin partitura (enlace) ${ }^{3}$, en este caso con ayuda de la partitura general (anexo I). Ante esta situación, los alumnos dispondrán de la partitura, pero no de la referencia por colores, por lo que habrá un número asociado a cada gama de color, siendo el uno la fila superior, el dos la fila justo debajo, y así sucesivamente. De este modo, los grupos rojo y azul tendrán cuatro números, el verde tres y el amarillo dos. Para esta segunda opción de interpretación, será obligatorio que el profesor cuente con un cronómetro, pues las entradas y salidas en la partitura general vienen indicadas sobre una barra de tiempo.

Es fundamental que el profesor indique el tempo al que se va a interpretar la figura de negra, para que todos los alumnos vayan simultáneamente. Incluso si el nivel de clase lo permite, se pueden hacer varias interpretaciones a distintas velocidades para que el alumnado observe in situ como influye el tempo en las

2. https://www.youtube.com/watch?v=My9AJX7B8LU [consultado el 14 de octubre de 2020].

3. https://www.youtube.com/watch?v=eggiQovjEBI [consultado el 14 de octubre de 2020]. 
distintas capas texturales que se van a crear y en el significado que aporta la música a la imagen en función de su carácter.

Con las mismas partituras e indicaciones, los alumnos pueden cambiar de grupo para abordar la actividad desde un punto de vista distinto. Esto favorecerá la dinámica de la clase ya que la atención del alumno no caerá al tener una nueva partitura y un nuevo instrumento para explorar.

Con esta actividad, el alumnado no solo comprende el proceso creativo de Ligeti a través de la práctica, que siempre causa mayor impacto y permanece por más tiempo en la memoria, sino que también practica la lectura musical, la interpretación tanto individual como en grupo y la relación música e imagen, trabajando así varios de los objetivos del currículo.

La siguiente pieza que se propone para trabajar en clase es Lux Aeterna, la segunda partitura de Ligeti que aparece en la película. La dinámica de trabajo será similar a la actividad anterior. Nuevamente se vuelven a agrupar los alumnos en cuatro grupos, que pueden ser los mismos si con anterioridad han funcionado bien. Sí se aconseja que en cualquier caso los alumnos cambien a instrumentos que no hayan tocado con anterioridad. La novedad esta vez reside en que la composición de los grupos rítmicos correrá a cargo de los propios alumnos. Para ello, una vez asignado el o los instrumentos a cada grupo, se les hará entrega de las partituras adjuntas en los anexos VII-X, en las que el espacio para la interpretación musical asignada a cada color estará vacío, de modo que entre ellos puedan elegir varios motivos que contenga negras, corcheas y semicorcheas. Como ya han realizado la interpretación anterior, comprenderán fácilmente la dinámica de esta actividad y el objetivo final.

Al igual que en la escena del «Kyrie», se puede trabajar con el enlace al vídeo Lux aeterna con partitura (enlace) ${ }^{4}$ la primera vez, y a posteriori con el vídeo Lux aeterna sin partitura (enlace) $)^{5}$, en la que el profesor ejerce de director con la partitura general adjunta en anexo VI, del mismo modo que ya se ha explicado en la actividad anterior.

Si en la interpretación del «Kyrie» se proponía al profesor la opción de que los alumnos cambiasen de grupo tras una o varias interpretaciones, para así mejorar la dinámica de la clase y favorecer el aprendizaje de otros instrumentos y patrones rítmicos, en esta actividad la propuesta se hace aún con más hincapié, puesto que al cambiar de grupos, pongamos por ejemplo que los alumnos de color azul pasan a rojo, los alumnos de este último grupo tendrán que explicarles a los nuevos su

4. https://www.youtube.com/watch?v=_bWXN9fYY3g [consultado el 14 de octubre de 2020].

5. https://www.youtube.com/watch?v=jwurys3eKHA [consultado el 14 de octubre de 2020]. 
composición musical. De este modo, el alumno prueba el papel de compositor durante unos momentos, explicando y revisando su propia partitura en manos de otro intérprete. Como en la actividad anterior, es fundamental que el profesor indique la velocidad de pulso para garantizar la simultaneidad entre todos y de nuevo se aconseja la interpretación de la pieza a varias velocidades para observar la influencia de esta en el carácter de la partitura.

Con esta actividad se refuerza la comprensión de composición musical por texturas, que además en esta ocasión han sido creadas por ellos, por lo que se estimula la creatividad y el trabajo en grupo, al tener que decidir estos patrones entre todos los miembros del mismo color. También se trabajan la lectura musical, con un nuevo compás diferente al anterior; la interpretación individual y grupal, y la relación entre música e imagen, desarrollando nuevamente varios objetivos del currículo.

La última pieza que se propone en este trabajo es Atmosphères, que aparece junto al «Kyrie» hacia el final de la película.

De nuevo la dinámica de trabajo es similar a las anteriores, aunque en este caso no será necesario dividir la clase en grupos, bastará con que cada alumno escoja un color a seguir, pues deberán improvisar de manera individual. En esta ocasión, la tabla con las gamas de colores aparece sin motivos musicales, únicamente la indicación de compás y las figuras musicales que deberán usar en su interpretación. Así, dentro del color rojo, por ejemplo, el alumno deberá improvisar con negras y corcheas sobre un compás de cuatro por cuatro cuando aparezca el segundo bloque de color. Las partituras para esta pieza se encuentran en los anexos XII-XV, mientras que la partitura general para el profesor, en el anexo XI.

Para que la actividad se realice de manera adecuada, el docente debe preocuparse de que todos los colores hayan sido escogidos. Como en las actividades anteriores, se aconseja realizar primero una interpretación con el vídeo Atmosphères con partitura (enlace $)^{6}$ para después pasar a las indicaciones del profesor como director con el vídeo Atmosphères sin partitura (enlace) ${ }^{7}$. Para esta interpretación se aconseja el uso de objetos en lugar de instrumentos convencionales, como podrían ser lápices, papel de periódico, latas, etc., así como no hay indicaciones sobre la interpretación de las figuras musicales, estimulando la creatividad en la búsqueda de nuevos timbres y sonidos por parte del alumno.

Con esta última actividad se fomenta especialmente la creación espontánea gracias a la improvisación, por lo que nuevamente estamos trabajando sobre objetivos indicados en el currículo de la asignatura.

6. https://www.youtube.com/watch?v=S6LAsiNSmJE [consultado el 14 de octubre de 2020].

7. https://www.youtube.com/watch?v=giJ4dbolI4U [consultado el 14 de octubre de 2020]. 
Tras la última interpretación, el profesor puede volver a comentar algunos aspectos teóricos sobre Ligeti y su música, a modo de repaso sobre todo lo trabajado y explicado en relación a la música textural durante estas sesiones, cerrando así el marco teórico en el que se encuadran todas las actividades realizadas, de modo que el alumno no se disperse o pierda la noción de lo que se ha realizado en estos últimos días de clase. Incluso, tras esta breve intervención, se aconseja dar la palabra al alumnado para crear un debate corto sobre la música textural a modo de conclusión.

\section{CONCLUSIONES}

Apoyándonos en la investigación realizada sobre los proyectos llevados a cabo por otros docentes y en mi propia experiencia, considero que tanto los materiales aportados como las actividades propuestas serán de utilidad en el futuro a la hora de acercar la música de Ligeti y el concepto de creación textural a los alumnos por varios motivos.

En primer lugar, quiero destacar la buena acogida que tiene entre el alumnado el uso de medios audiovisuales, que por lo general facilita enormemente la recepción de los contenidos pedagógicos que queremos que lleguen al alumno. En este sentido, el hecho de orientar todas las actividades hacia la práctica interpretativa, incluyendo improvisación, creación y trabajo en equipo, siempre resulta una manera lúdica y entretenida de aprender para alumnos adolescentes. Otro punto a tener en cuenta en la valoración positiva de las actividades es la libertad de la que dispone el enseñante para hacer modificaciones o adaptaciones sobre estas, teniendo siempre como base el vídeo de la pieza a interpretar. Por todo esto, a pesar de no haber podido probar in situ la propuesta didáctica, estoy seguro de que las actividades tendrían muy buena acogida entre el alumnado de Música.

El segundo aspecto a tener en cuenta, y quizás el más importante, es la validez pedagógica. De nada sirve que el alumno reciba con entusiasmo las actividades que el profesor le propone si tras haberlas realizado no ha adquirido ningún conocimiento nuevo sobre la materia. Como ya se describió en la introducción del artículo, el objetivo que se plantea no es que el alumno conozca con profundidad la música de Ligeti, pues no tendría sentido, sino que perciba y comprenda el concepto de creación musical por texturas o música textural. Y todas las actividades están orientadas hacia este objetivo final. En primer lugar visualmente, ya que en los vídeos la densidad de la música de Ligeti se corresponde en cada momento con el número de colores que aparecen, mientras que, en los momentos de la pieza en los que la densidad es menor, solo vemos en pantalla una o dos líneas de colores, por lo que el alumno percibe clara y directamente esta relación visual y auditiva, siendo evidente la relación más capas instrumentales-más densidad y menos capas 
instrumentales-menos densidad. Si bien el objetivo de la primera actividad está orientado hacia esta recepción más visual y más sencilla para los alumnos, con las variaciones introducidas posteriormente en la segunda y tercera actividad, el punto de atención se orienta más hacia la percepción auditiva, siendo el mejor ejemplo la última actividad en la que cada alumno crea una voz independiente al resto, formando en el aula un coro u orquesta de veinticinco alumnos, donde la gran masa sonora de los puntos culminantes de la pieza evidenciará aún más este concepto de creación sonora. Por lo que en el aspecto pedagógico, aun no pudiendo haber llevado al aula la actividad, tampoco me cabe duda de que funcionará, por usar en primer lugar el apoyo visual, principalmente, y el creativo y auditivo a continuación, todo ello con la idea de capas texturales de fondo.

Finalizo las conclusiones a este trabajo dedicando unas líneas al nivel de la propuesta didáctica. Si bien por cuestiones prácticas está orientada al tercer curso de Secundaria, todo el material puede adaptarse a distintos niveles educativos, variando la dificultad de la interpretación instrumental e incluso los motivos musicales. Por lo que considero que puede resultar de interés para docentes de toda la comunidad educativa de Secundaria y Bachillerato.

\section{BIBLIOGRAFÍA}

Agel, J. (1970). The making of Kubrick's 2001. Chicago: New Amer Library.

Alda, R. (2000). 2001 La odisea continúa. Madrid: Jaguar.

Archilla, H. (2017). La banda sonora en el aula de música a través de los Oscar. Alicante: Ediciones Letra de Palo.

Castillo Álvarez, D. y Prieto Alberola, R. (2003). Medios audiovisuales: una estrategia para mejorar la motivación. Revista Música y educación, 56, 83-94.

Centeno, J. L. (2016). La música de Ligeti en 2001: Una odisea del espacio de Stanley Kubrick (Tesis doctoral). Valladolid: Ediciones de la Universidad de Valladolid.

Chion, M. (2001). Kubrick's Cinema Odyssey. Londres: BFI.

Climent, M. (2000). Kubrick. Madrid: Akal.

Galbis, V. (2017). Las texturas musicales: Propuestas didácticas para un aprendizaje en clave audiovisual. Alicante: Ediciones Letra de Palo.

Gengaro, L. (2014). Listening to Stanley Kubrick: The music in his films. Londres: Rowman and Littlefield.

Geruld, C. (1973). Filmguide to 2001: A Space Odyssey. Bloomington: Indiana University Press.

Griffiths, P. (1983). György Ligeti. Londres: Robson Books.

Grout, D. y Palisca, C. (1984). Historia de la música occidental, vol. 2. Madrid: Alianza Editorial. 
Martín Félez, D. (2010). La banda sonora en las producciones audiovisuales y su aplicación en educación infantil, primaria y secundaria: una propuesta de investigación-acción. Madrid: Bubok Publishing.

Montoya Rubio, J. C. (2007). La música de cine como estrategia educativa. Ensayos, 22, 99-124.

Montoya Rubio, J. C. (2010). Música y medios audiovisuales. Planteamientos didácticos en el marco de la educación musical. Salamanca: Ediciones de la Universidad.

North, A. (1970). Alex North's comments on 2001. Chicago: The New American Library.

Olarte Martínez, M.; Montoya Rubio, J. C.; Martín Félez, D. y Mosquera Fernández, A. (2011). La incorporación de los medios audiovisuales en la enseñanza de la música. Docencia e Investigación, 21.

Padrol, J. (2008). La música de Stanley Kubrick para 2001. Madrid: Imágica Ediciones.

Ediciones Universidad de Salamanca / అ@@ PopularMusicResearchToday,2,2(2020),pp.61-78 